Lima, 5-6 de septiembre de 2007

\title{
Un evento para no olvidar: «Coloquio Internacional Memoria, Violencia y Movimientos Sociales en los Países Andinos»
}

Lima, 5-6 de septiembre de 2007

\section{Marté Sánchez Villagómez}

\section{(2) OpenEdition}

12 Journals

\section{Edición electrónica}

URL: http://journals.openedition.org/bifea/3766

DOI: $10.4000 /$ bifea.3766

ISSN: 2076-5827

Editor

Institut Français d'Études Andines

\section{Edición impresa}

Fecha de publicación: 1 diciembre 2007

Paginación: 465-466

ISSN: 0303-7495

\section{Referencia electrónica}

Marté Sánchez Villagómez, « Un evento para no olvidar: «Coloquio Internacional Memoria, Violencia y Movimientos Sociales en los Países Andinos» », Bulletin de l'Institut français d'études andines [En línea], 36 (3) | 2007, Publicado el 01 junio 2008, consultado el 12 diciembre 2020. URL : http://

journals.openedition.org/bifea/3766 ; DOI : https://doi.org/10.4000/bifea.3766

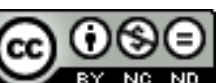

Les contenus du Bulletin de l'Institut français d'études andines sont mis à disposition selon les termes de la licence Creative Commons Attribution - Pas d'Utilisation Commerciale - Pas de Modification 4.0 International. 


\section{UN EVENTO PARA NO OLVIDAR: «COLOQUIO INTERNACIONAL MEMORIA, VIOLENCIA Y MOVIMIENTOS SOCIALES EN LOS PAÍSES ANDINOS»}

Lima, 5-6 de septiembre de 2007

Los días 5 y 6 de septiembre del presente año se convirtieron en un verdadero espacio de discusión académica cuya razón fue establecer un diálogo regional, que coincidentemente encajaron dentro del marco conmemorativo por el IV aniversario de la presentación del Informe Final de la Comisión de la Verdad y Reconciliación del Perú.

Los procesos de violencia en los países andinos han cobrado por lo general la forma de masivas violaciones de Derechos Humanos, inclusive de crímenes contra la humanidad. Por ello debemos preguntarnos de qué modo dichos procesos han estado relacionados con la negación de reconocimiento a amplios sectores poblacionales, principalmente a la población definida como indígena. Por ello la necesidad de un espacio de discusión internacional para que, desde diversas perspectivas sociales y tomando como campo de análisis la realidad social y política de los países andinos (Colombia, Ecuador, Perú y Bolivia), se planteen explicaciones de los acontecimientos de Violencia, memoria y movimientos sociales sucedidos en estos espacios nacionales.

En ese sentido el Coloquio Internacional Memoria, violencia y movimientos sociales en los países andinos abordó cuatro ejes temáticos:

- la experiencia de dictaduras que han gobernado en países de la subregión desde la segunda mitad del siglo XX y que han desplegado métodos de represión social violenta contra movimientos sociales;

- los movimientos sociales confrontados por las dictaduras, poniendo énfasis en aquellos que han sido portadores de demandas de reconocimiento;

- las memorias sociales elaboradas sobre esas experiencias de violencia;

- finalmente, la persistencia de movimientos sociales en lucha por reconocimiento.

El evento ha permitido la inclusión de las memorias postergadas por las historias nacionales; asimismo permitió llamar la atención sobre las tareas pendientes de las sociedades andinas frente a sus experiencias pasadas, pero no lejanas, de violencia interna.

El coloquio fue sentido como un esfuerzo necesario en contra del olvido y de las memorias excluyentes; además, se instaló dentro de la perspectiva de reflexión crítica en busca de encontrar alternativas que faciliten los caminos que lleven a una reconciliación, vista esta última en proyección futura.

El Evento Internacional Memoria, violencia y movimientos sociales en los países andinos que se realizado en Lima-Perú logró reunir especialista de países hermanos y que han tenido que pasar por similares circunstancias y en algunos casos aún viven dramáticos procesos de alta conflictividad social, en ese sentido la memoria del pasado convive cotidianamente con una realidad igual o más violenta que la del pasado que se resiste a ser procesada.

Las realidades sociales de los países de Colombia, Ecuador, Bolivia y Perú fueron puestas en debate comparativo y también bajo miradas regionales, esta última fue la particularidad que mostró el caso peruano.

El Coloquio internacional dio inicio a sus actividades con las palabras de Vicerrector Académico de la PUCP Dr. Efraín Gonzáles de Olarte y el Consejero Regional de Cooperación de la Embajada de Francia Dr. Bernard Grau. Asimismo se dieron cita en el coloquio intelectuales como Gisella Cánepa, Carlos Iván Degregori, Gonzalo Portocarrero, 
Ramón Pajuelo, Shirley Orozco, Gonzalo Sánchez, María Victoria Uribe, Leslie Villapolo, Anahí Durand, Hortensia Muñoz, Marté Sánchez, Ricardo Caro, Valérie Robin, Félix Reátegui y Javier Torres.

Finalmente, es necesario decir que esta experiencia académica no hubiese sido posible de realizar sin el auspicio de Instituto Francés de Estudios Andinos (IFEA), Servicios Educativos Rurales (SER), Instituto de Democracia y Derechos Humanos de la Pontificia Universidad Católica del Perú (IDEHPUCP), La Cooperación Regional Francesa para los Países Andinos y el Inwent-Oficina Regional para los Países Andinos.

Marté SÁNCHEZ VILLAGÓMEZ 